\title{
Systemic Inflammation and Astrocyte Reactivity in the Neuropsychiatric Sequelae of COVID-19: Focus on Autism Spectrum Disorders
}

\author{
Marta Valenza ${ }^{1}$, Luca Steardo $\mathrm{Jr}^{2}{ }^{2}$, Luca Steardo ${ }^{1,3 *}$, Alexei Verkhratsky ${ }^{4,5,6}$ and \\ Caterina Scuderi ${ }^{1 *}$ \\ 'Department of Physiology and Pharmacology "Vittorio Erspamer", SAPIENZA University of Rome, Rome, Italy, ${ }^{2}$ Psychiatric \\ Unit, Department of Health Sciences, University Magna Graecia of Catanzaro, Catanzaro, Italy, ${ }^{3}$ Università Telematica \\ Giustino Fortunato, Benevento, Italy, ${ }^{4}$ Faculty of Biology, Medicine and Health, The University of Manchester, Manchester, \\ United Kingdom, ${ }^{5}$ Achucarro Center for Neuroscience, IKERBASQUE, Billbao, Spain, ${ }^{6}$ Department of Stem Cell Biology, \\ State Research Institute Centre for Innovative Medicine, Vilnius, Lithuania
}

Keywords: astrocytes, autism spectrum disorders, COVID-19, microglia, neuroinflammation, reactive gliosis, astrogliosis, SARS-CoV-2

OPEN ACCESS

Edited by:

Marta Fumagalli,

University of Milan, Italy

Reviewed by:

Annalisa Buffo,

University of Turin, Italy

*Correspondence:

Luca Steardo

luca.steardo@uniroma1.it

Caterina Scuderi

caterina.scuderi@uniroma1.it

Specialty section:

This article was submitted to

Non-Neuronal Cells,

a section of the journal

Frontiers in Cellular Neuroscience

Received: 27 July 2021 Accepted: 02 November 2021 Published: 29 November 2021

Citation:

Valenza M, Steardo L Jr, Steardo L, Verkhratsky A and Scuderi C (2021)

Systemic Inflammation and Astrocyte

Reactivity in the Neuropsychiatric

Sequelae of COVID-19: Focus on

Autism Spectrum Disorders.

Front. Cell. Neurosci. 15:748136.

doi: 10.3389/fncel.2021.748136

\section{INTRODUCTION}

\section{The Neurotropism of the SARS-CoV-2}

The coronavirus disease (COVID)-19, caused by the severe acute respiratory syndrome coronavirus 2 (SARS-CoV-2), was initially regarded as a specific lung disease. In the course of pandemic evidence for extrapulmonary manifestations has mounted. In particular, neurologic symptoms include anosmia and ageusia, encephalitis, seizures, stroke, confusion and delirium (Desforges et al., 2019; Asadi-Pooya and Simani, 2020; Vaira et al., 2020; Deng et al., 2021; Hugon et al., 2021). Neurological and psychiatric also accompany long-lasting complications of the disease, occurring in patients during the first 6 months after viral infection, while the risk for such sequelae seems to be greatest in case of severe COVID-19 (Fernandez-de-Las-Penas, 2021; Taquet et al., 2021). It has been proposed that the human immune response induced by SARS-CoV-2 develops in two phases. The constitutive adaptive immune response is mobilised at the beginning of the disease confronting actively replicating virus (Shi et al., 2020). A second phase, that occurs in severe cases of COVID-19, is defined as severe acute respiratory distress syndrome (ARDS), characterised by the hyperactivation of the immune system, commonly referred to as "cytokine storm," with a massive systemic release of proinflammatory mediators, cytokines, and chemokines (Polidoro et al., 2020). This hyperactive immune response and the subsequent cytokine load are now considered among major pathophysiological hallmarks in COVID-19 patients (Abdin et al., 2020). Their impact upon organs, brain including, contributes to the multi-system pathology observed in patients (Gerges Harb et al., 2020; Moore and June, 2020).

Similarly to other members of the group 2 of the $\beta$-coronavirus family, SARS-CoV- 2 can enter and infest the central nervous system (CNS) (Lau et al., 2004; Bergmann et al., 2006; Steardo et al., 2020a; Zhou et al., 2020). The most studied and acknowledged route for viral entry is through binding to the angiotensin-converting enzyme 2 (ACE2), expressed in the CNS, mostly by endothelial cells, but also found in neurones and neuroglia (Zeisel et al., 2015; Gowrisankar and Clark, 2016; Nemoto et al., 2020). Consistent with the frequent alterations of smell and taste perception reported in COVID-19, SARS-CoV-2 is thought to invade 
the olfactory system and spread to the brain stem, possibly compromising the respiratory centres (Giacomelli et al., 2020; Lechien et al., 2020; Spinato et al., 2020; Wolfel et al., 2020). The virus could penetrate also through the median eminence, where endotheliocytes and tanycytes express ACE2, thus reaching the hypothalamus (Satarker and Nampoothiri, 2020), and from there spreading to the entire brain. Another possible route is the infiltration of immune cells carrying the virus into the brain [a "viral reservoir" (Iadecola et al., 2020; Tavcar et al., 2021)]. Vessels, meninges, and the choroid plexus have been proposed to act as entry points for infected monocytes, neutrophils, and T cells (Merad and Martin, 2020). However, conclusive evidence of infection through this route is yet to be provided. Lastly, a leaky or dysfunctional blood-brain barrier (BBB) could facilitate the entry of the virus, as seen for other infections (Cisneros and Ghorpade, 2012). Systemic inflammation damages glia limitans and the $\mathrm{BBB}$, thus the hyperreactive immune response triggered by SARS-CoV-2 could compromise the integrity of the BBB (Valenza et al., 2020). Moreover, comorbidities often associated with severe COVID-19, e.g., CNS hypoxia due to respiratory failure, thrombotic microangiopathy, or preexisting neurological diseases, could have already altered the BBB permeability facilitating SARS-CoV-2 invasion of the brain (Erickson et al., 2021).

\section{Astrocytes Response to Viral Infections, Including SARS-CoV-2}

Any insult to the CNS, including viruses, triggers glial reactivity (Verkhratsky et al., 2017; Zorec et al., 2019; Escartin et al., 2021) aimed at restoring the lost homeostasis. At the same time, during viral infections, astrocytes and microglia may also become long-term viral reservoirs in the absence of efficient innate immune-mediated clearance. Viruses-induced rise in IL$1 \beta$ and TNF- $\alpha$ may change astrocyte metabolism, thus impairing neuronal energy support (Gavillet et al., 2008; Soung and Klein, 2018). In human immunodeficiency virus (HIV) infection, reactive astrocytes overproduce cytokines and chemokines able to reduce viral replication (Zhou et al., 2004; Li et al., 2011). Broad hyperplasia of glial cells, with necrosis of neurones, and encephalic oedema have been reported in a SARS-CoV-1 patient (Xu et al., 2005). Several case reports indicate that SARS-CoV2 affects astrocytes. A rise in the glial fibrillary acidic protein (GFAP), commonly regarded as a marker of astrocyte reactivity, was found in the white matter of a COVID-19 patient with encephalomyelitis-like brain damage (Reichard et al., 2020). Plasma levels of GFAP were elevated in moderate/severe stages of COVID-19 suggesting that astrogliosis is an early CNS response to SARS-CoV-2 infection (Kanberg et al., 2020). In a COVID-19related acute necrotising encephalopathy, 19 days after the onset of symptoms and even after testing negative twice for COVID-19, the SARS-CoV-2 was detected in the CSF together with extremely high levels of both the neurofilament light-chain protein (NfL), a biomarker predictive of intra-axonal neuronal injury, and GFAP (Virhammar et al., 2020). These clinical data indicate that astrocytes enter a reactive state in COVID-19 patients. Moreover, the damage to the $\mathrm{BBB}$ and the strong lymphopenia observed during COVID-19 could promote the persistence of the virus into the brain, thus sustaining neuroinflammation and reactive gliosis. The resulting brain tissue alteration could explain some of the clinical features observed in COVID-19 patients who, despite resolved pneumonia, present cognitive impairments associated with behavioural changes (Sasannejad et al., 2019; Steardo et al., 2020b, 2021; Tremblay et al., 2020; Boldrini et al., 2021).

\section{COVID-19 During Pregnancy}

Pregnant women are considered at high risk to develop severe COVID-19, despite case reports indicate that the disease severity is similar to the general population (Mullins et al., 2020; Rasmussen et al., 2020; Zaigham and Andersson, 2020). Infections with SARS-CoV-2 during pregnancy have been associated with preterm delivery, intrauterine growth retardation, and perinatal deaths (Diriba et al., 2020; Huntley et al., 2020; Woodworth et al., 2020; Bellos et al., 2021). A retrospective study shows that SARS-CoV-2 infection during pregnancy is not associated with an increased risk of spontaneous abortion and spontaneous preterm birth (Yan et al., 2020). Studies reported zero to very low rate of vertical transmission from the mother to the foetus. Some case reports highlighted the presence of both $\mathrm{M}$ and $\mathrm{G}$ immunoglobulins against SARS$\mathrm{CoV}-2$ at birth in three neonates whose mothers presented with COVID-19 23 days before delivery (Dong et al., 2020; Zeng et al., 2020). In a cohort of 64 pregnant women who tested positive for SARS-CoV-2, 12 had severe to critical COVID19, but neither placental infection nor vertical transmission occurred (Edlow et al., 2020). In contrast, one case of SARS-CoV-2 transplacental transmission has been reported, in which both the placental tissue and the amniotic fluid were positive as maternal and neonatal blood samples. Of note, mother's infection occurred at the last weeks of gestation (Vivanti et al., 2020).

\section{COVID-19 and Neuropsychiatric Sequelae: Focus on Autism Spectrum Disorders}

Epidemiologic data correlate maternal infections with several neuropsychiatric disorders, including autism spectrum disorders (ASD) (Minakova and Warner, 2018). Autism and ASD are terms indistinctively used to define a group of heterogeneous neurodevelopmental disorders affecting about $1 \%$ of the world's population (Elsabbagh et al., 2012; Ilieva and Lau, 2020). Precise aetiology of ASD is still unknown. Both genetic and environmental factors are thought to contribute, including an increase of inflammatory cytokines, abnormal immune responses, and the presence of autoantibodies (Ormstad et al., 2018; Mazon-Cabrera et al., 2019). Some of these features are in common with those considered risk factors for severe COVID-19. Therefore, some authors have speculated that ASD could be a risk factor for SARS-CoV-2 infection and COVID-19 outcome (Lima et al., 2020; Brown et al., 2021). 


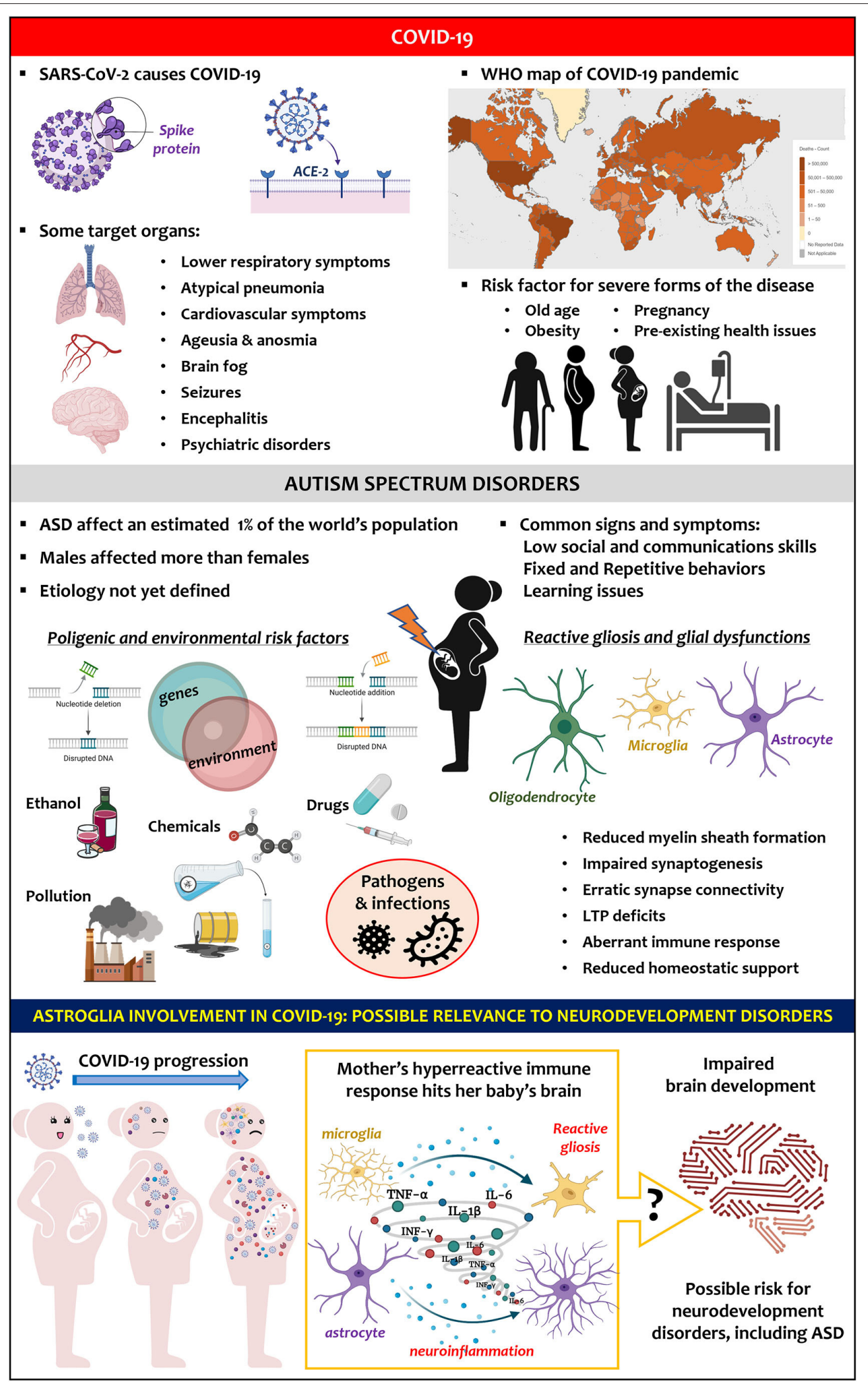

FIGURE 1 | Key facts on SARS-CoV-2 infection and COVID-19 pandemic (upper panel). Key facts on ASD (middle panel). Hypothesis (lower panel): COVID-19-induced hyperreactive immune response in pregnant women could trigger astroglia reactivity in the baby's brain, altering its development and favouring neurodevelopment disorders, including ASD. 
Numerous environmental factors are thought to increase the risk for ASD, as neurotoxins, air pollutants, and drugs (Riley and McGee, 2005; Grandjean and Landrigan, 2006; Brown, 2012; Krakowiak et al., 2012; Saxena et al., 2020) as well as perinatal infections (Hornig and Lipkin, 2001). Evidence supporting a link between infection during pregnancy and ASD incidence is increasing (Bilbo et al., 2018). A two-fold increase of ASD has been documented following maternal infection with influenza virus, but not with common infections, such as cystitis or genital herpes (Atladottir et al., 2012; Croen et al., 2019). Maternal diagnosis of viral or bacterial infection, regardless of the timing of the infection during pregnancy, has been associated with approximately a $30 \%$ increase in ASD risk for their children (Lee et al., 2015). Thus, some authors suggested that prenatal viral infection could represent the principal non-genetic cause of autism (Ciaranello and Ciaranello, 1995; Depino, 2018). To date, there is no evidence documenting a causal link between COVID-19 and ASD. However, this neurodevelopmental disease could be diagnosed few years after birth, thus upcoming reports could provide data for ASD incidence in SARS-CoV-2 infected mothers.

\section{Reactive Astrocytes in the Foetal Brain: Possible Link to Autism Spectrum Disorders?}

Despite the lack of evidence, a link between maternal SARSCoV-2 infection and ASD can be speculated. It is well known that the perinatal environment markedly affects brain development and function, and, for this reason, some of the cellular and molecular alterations caused by SARS-CoV-2 could hypothetically promote ASD (Figure 1) (Steinman, 2020a; Rasile et al., 2021). Above all, the activation of the maternal immune system with the subsequent exposure of the foetus to high levels of cytokines, chemokines, and other mediators of inflammation through maternal serum, placenta, and amniotic fluid may impact on the brain (Knuesel et al., 2014). Foetal exposure to infections is accompanied by modifications in the expression of proinflammatory mediators, reactive gliosis and altered expression of genes involved in brain development, all previously linked with ASD (Pardo and Eberhart, 2007; Li et al., 2009; Zeidan-Chulia et al., 2014; Liao et al., 2020). Among several cytokines, IL-6 has attracted much attention mainly because it is elevated in cases of complicated forms of COVID19 and correlates with adverse clinical outcomes (Chen et al., 2020; Zhu et al., 2020). Incidentally, IL-6 plays a key role also in ASD. Data correlated the in utero exposure to IL-6 and ASD-related features (Smith et al., 2007). Increased IL-6 levels were detected in the brains of ASD patients compared with controls subjects ( $\mathrm{Li}$ et al., 2009). An increase in IL-6 placental levels was found to negatively correlate with insulinlike growth factor 1 (IGF-1) (Patterson, 2009). This is relevant to ASD since autistic children below four years old show lower concentrations of IGF-1 than age-matched controls (Riikonen et al., 2006). IGF-1 participates in several physiologically relevant neuroprotective mechanisms and exerts significant effects on foetal and perinatal brain growth, including neurogenesis and synaptogenesis (Steinman, 2020b). The hyperactivation of systemic immune response and specifically the increase in circulating IL-6 in a mother infected by SARS-CoV-2 could expose the foetus to an aberrant inflammatory environment, which is deleterious for the developing brain. As we mentioned before, SARS-CoV-2 triggers astrogliosis and microgliosis fostering remodelling of brain circuits through the synthesis and release of numerous mediators. Compromised glial activity coupled with a predisposing genetic background has been proposed to contribute to ASD pathogenesis (Zeidan-Chulia et al., 2014; Petrelli et al., 2016). Furthermore, studies on animal models are consistent with human observations demonstrating astrocyte abnormalities in ASD (Boldrini et al., 2018; Scuderi and Verkhratsky, 2020). For instance, some of the genes contributing to brain development and conferring susceptibility to ASD are highly expressed in astrocytes (Stogsdill et al., 2017; Sakers and Eroglu, 2019). Post-mortem brain samples of ASD subjects show abnormal levels of cytokines and chemokines together with signs of astrogliosis and microgliosis (Liao et al., 2020). Given the role of glia in regulating synaptic activity, a sustained presence of reactive glia could explain the region-specific altered connectivity seen in ASD patients, as well as their cognitive and behavioural traits (Just et al., 2007; Assaf et al., 2010; Supekar et al., 2013).

\section{CONCLUSIONS}

Although COVID-19 and ASD differ in their aetiology and pathobiology, they share a single common feature: both are associated with the aberrant activation of the immune system and establishment of a pro-inflammatory environment. Growing evidence indicates the role of glial cells in both pathologies. The involvement of glia in the neurological consequences of COVID19 has recently been documented, whereas the neuropathological potential of glia in ASD is established. No data are available yet on the consequences of foetal exposure to SARS-CoV-2 infection. However, coronaviruses, like SARS-CoV-2, have the potential to provoke adverse maternal or perinatal outcomes. Generally, maternal infection and fever during pregnancy double the risk of ASD in infants. Foetal exposure to infections is accompanied by an increased expression of markers of glia reactivity and proinflammatory mediators as well as an altered expression of genes involved in brain development. Therefore, at least hypothetically, SARS-CoV-2 infection may impair the baby's brain development by boosting cytokines circulation in the pregnant mother, potentially increasing the risk for ASD. The reactivity of neuroglia and in particular of astrocytes could mediate these adverse effects on the foetal brain.

The validity of this hypothesis is yet impossible to confirm because of the scarcity of data, and yet it is crucial to monitor babies born from mothers who suffered from COVID-19 during pregnancy, for the potential risk for ASD as well as other neurodevelopment pathologies. 


\section{AUTHOR CONTRIBUTIONS}

$\mathrm{MV}, \mathrm{AV}$, and CS conceived and wrote the review manuscript. MV prepared the figure. All authors contributed to the design, writing, and revision of the paper.

\section{FUNDING}

CS was supported by the Italian Ministry of University and Research (MUR) (PRIN prot. 2015KP7T2Y_002) and

\section{REFERENCES}

Abdin, S. M., Elgendy, S. M., Alyammahi, S. K., Alhamad, D. W., and Omar, H. A. (2020). Tackling the cytokine storm in COVID-19, challenges and hopes. Life Sci. 257, 118054. doi: 10.1016/j.lfs.2020.118054

Asadi-Pooya, A. A., and Simani, L. (2020). Central nervous system manifestations of COVID-19: A systematic review. J. Neurol. Sci. 413, 116832. doi: 10.1016/j.jns.2020.116832

Assaf, M., Jagannathan, K., Calhoun, V. D., Miller, L., Stevens, M. C., Sahl, R., et al. (2010). Abnormal functional connectivity of default mode subnetworks in autism spectrum disorder patients. Neuroimage 53, 247-256. doi: 10.1016/j.neuroimage.2010.05.067

Atladottir, H. O., Henriksen, T. B., Schendel, D. E., and Parner, E. T. (2012). Autism after infection, febrile episodes, and antibiotic use during pregnancy: an exploratory study. Pediatrics 130, e1447-1454. doi: 10.1542/peds.2012-1107

Bellos, I., Pandita, A., and Panza, R. (2021). Maternal and perinatal outcomes in pregnant women infected by SARS-CoV-2: a meta-analysis. Eur. J. Obstet. Gynecol. Reprod. Biol. 256, 194-204. doi: 10.1016/j.ejogrb.2020.11.038

Bergmann, C. C., Lane, T. E., and Stohlman, S. A. (2006). Coronavirus infection of the central nervous system: host-virus stand-off. Nat. Rev. Microbiol. 4, 121-132. doi: 10.1038/nrmicro1343

Bilbo, S. D., Block, C. L., Bolton, J. L., Hanamsagar, R., and Tran, P. K. (2018). Beyond infection - Maternal immune activation by environmental factors, microglial development, and relevance for autism spectrum disorders. Exp. Neurol. 299, 241-51. doi: 10.1016/j.expneurol.2017.07.002

Boldrini, M., Canoll, P. D., and Klein, R. S. (2021). How COVID-19 affects the brain. JAMA Psychiatry 78, 682-683. doi: 10.1001/jamapsychiatry.2021.0500

Bronzuoli, M. R., Facchinetti, R., Ingrassia, D., Sarvadio, M., Schiavi, S., Steardo, L., et al. (2018). Neuroglia in the autistic brain: evidence from a preclinical model. Mol. Autism 9:66. doi: 10.1186/s13229-018-0254-0

Brown, A. S. (2012). Epidemiologic studies of exposure to prenatal infection and risk of schizophrenia and autism. Dev. Neurobiol. 72, 1272-1276. doi: 10.1002/dneu.22024

Brown, G. M., Karthikeyan, R., Pandi-Perumal, S. R., and Cardinali, D. P. (2021). Autism Spectrum Disorder patients may be susceptible to COVID19 disease due to deficiency in melatonin. Med. Hypotheses 149, 110544. doi: 10.1016/j.mehy.2021.110544

Chen, X., Zhao, B., Qu, Y., Chen, Y., Xiong, J., Feng, Y., et al. (2020). Detectable serum severe acute respiratory syndrome coronavirus 2 viral load (RNAemia) is closely correlated with drastically elevated interleukin 6 level in critically ill patients with coronavirus disease 2019. Clin. Infect. Dis. 71, 1937-1942. doi: 10.1093/cid/ciaa449

Ciaranello, A. L., and Ciaranello, R. D. (1995). The neurobiology of infantile autism. Annu. Rev. Neurosci. 18, 101-128. doi: 10.1146/annurev.ne.18.030195.000533

Cisneros, I. E., and Ghorpade, A. (2012). HIV-1, methamphetamine and astrocyte glutamate regulation: combined excitotoxic implications for neuro-AIDS. Curr. HIV Res. 10, 392-406. doi: 10.2174/157016212802 138832

Croen, L. A., Qian, Y., Ashwood, P., Zerbo, O., Schendel, D., Pinto-Martin, J., et al. (2019). Infection and Fever in Pregnancy and Autism Spectrum Disorders: Findings from the Study to Explore Early Development. Autism. Res. 12, 1551-1561. doi: 10.1002/aur.2175 the SAPIENZA University of Rome (prot. RM11916B7 A8D0225).

\section{ACKNOWLEDGMENTS}

The COVID-19 pandemic world map presented in Figure 1 was taken from the World Health Organization dashboard website (https://covid19.who.int/) and reported with the permission of the Organization. The Figure was created using Biorender.com that granted permission to publish it.

Deng, J., Zhou, F., Hou, W., Silver, Z., Wong, C. Y., Chang, O., et al. (2021). The prevalence of depression, anxiety, and sleep disturbances in COVID-19 patients: a meta-analysis. Ann. N Y Acad. Sci. 1486, 90-111. doi: 10.1111/nyas.14506

Depino, A. M. (2018). Perinatal inflammation and adult psychopathology: From preclinical models to humans. Semin. Cell. Dev. Biol. 77, 104-114. doi: 10.1016/j.semcdb.2017.09.010

Desforges, M., Le Coupanec, A., Dubeau, P., Bourgouin, A., Lajoie, L., Dube, M., et al. (2019). Human coronaviruses and other respiratory viruses: underestimated opportunistic pathogens of the central nervous system? Viruses 12, 14. doi: 10.3390/v12010014

Diriba, K., Awulachew, E., and Getu, E. (2020). The effect of coronavirus infection (SARS-CoV-2, MERS-CoV, and SARS-CoV) during pregnancy and the possibility of vertical maternal-fetal transmission: a systematic review and meta-analysis. Eur. J. Med. Res. 25, 39. doi: 10.1186/s40001-02000439-w

Dong, L., Tian, J., He, S., Zhu, C., Wang, J., Liu, C., et al. (2020). Possible vertical transmission of SARS-CoV-2 from an infected mother to her newborn. JAMA 323, 1846-1848. doi: 10.1001/jama.2020.4621

Edlow, A. G., Li, J. Z., Collier, A. Y., Atyeo, C., James, K. E., Boatin, A. A., et al. (2020). Assessment of maternal and neonatal SARS-CoV2 viral load, transplacental antibody transfer, and placental pathology in pregnancies during the COVID-19 pandemic. JAMA Netw. Open. 3, e2030455. doi: 10.1001/jamanetworkopen.2020.30455

Elsabbagh, M., Divan, G., Koh, Y. J., Kim, Y. S., Kauchali, S., Marcin, C., et al. (2012). Global prevalence of autism and other pervasive developmental disorders. Autism. Res. 5, 160-179. doi: 10.1002/aur.239

Erickson, M. A., Rhea, E. M., Knopp, R. C., and Banks, W. A. (2021). Interactions of SARS-CoV-2 with the blood-brain barrier. Int. J. Mol. Sci. 22(5). doi: 10.3390/ijms22052681

Escartin, C., Galea, E., Lakatos, A., O’Callaghan, J. P., Petzold, G. C., SerranoPozo, A., et al. (2021). Reactive astrocyte nomenclature, definitions, and future directions. Nat. Neurosci. 24, 312-325. doi: 10.1038/s41593-020-00783-4

Fernandez-de-Las-Penas, D. C. (2021). Anxiety, depression and poor sleep quality as long-term post-COVID sequelae in previously hospitalized patients: a multicenter study. J. Infect. 83, 496-522. doi: 10.1016/j.jinf.2021.06.022

Gavillet, M., Allaman, I., and Magistretti, P. J. (2008). Modulation of astrocytic metabolic phenotype by proinflammatory cytokines. Glia 56, 975-989. doi: $10.1002 /$ glia.20671

Gerges Harb, J., Noureldine, H. A., Chedid, G., Eldine, M. N., Abdallah, D. A., Chedid, N. F., et al. (2020). SARS, MERS and COVID-19: clinical manifestations and organ-system complications: a mini review. Pathog. Dis. 78(4). doi: 10.1093/femspd/ftaa033

Giacomelli, A., Pezzati, L., Conti, F., Bernacchia, D., Siano, M., Oreni, L., et al. (2020). Self-reported olfactory and taste disorders in patients with severe acute respiratory coronavirus 2 infection: a cross-sectional study. Clin. Infect. Dis. 71, 889-890. doi: 10.1093/cid/ciaa330

Gowrisankar, Y. V., and Clark, M. A. (2016). Angiotensin II regulation of angiotensin-converting enzymes in spontaneously hypertensive rat primary astrocyte cultures. J. Neurochem. 138, 74-85. doi: 10.1111/jnc.13641

Grandjean, P., and Landrigan, P. J. (2006). Developmental neurotoxicity of industrial chemicals. Lancet 368, 2167-2178. doi: 10.1016/S0140-6736(06)69665-7 
Hornig, M., and Lipkin, W. I. (2001). Infectious and immune factors in the pathogenesis of neurodevelopmental disorders: epidemiology, hypotheses, and animal models. Ment. Retard. Dev. Disabil. Res. Rev. 7, 200-210. doi: $10.1002 / \mathrm{mrdd} .1028$

Hugon, J., Msika, E. F., Queneau, M., Farid, K., and Paquet, C. (2021). Long COVID: cognitive complaints (brain fog) and dysfunction of the cingulate cortex. J. Neurol. doi: 10.1007/s00415-021-10655-x

Huntley, B. J. F., Huntley, E. S., Di Mascio, D., Chen, T., Berghella, V., and Chauhan, S. P. (2020). Rates of maternal and perinatal mortality and vertical transmission in pregnancies complicated by severe acute respiratory syndrome coronavirus 2 (SARS-Co-V-2) infection: a systematic review. Obstet. Gynecol. 136, 303-312. doi: 10.1097/AOG.0000000000004010

Iadecola, C., Anrather, J., and Kamel, H. (2020). Effects of COVID-19 on the nervous system. Cell. 183, 16-27 e11. doi: 10.1016/j.cell.2020.08.028

Ilieva, M., and Lau, W. (2020). Autism. Progress in Molecular Biology and Translational Science. Elsevier.

Just, M. A., Cherkassky, V. L., Keller, T. A., Kana, R. K., and Minshew, N. J. (2007). Functional and anatomical cortical underconnectivity in autism: evidence from an FMRI study of an executive function task and corpus callosum morphometry. Cereb. Cortex. 17, 951-961. doi: 10.1093/cercor/bhl006

Kanberg, N., Ashton, N. J., Andersson, L. M., Yilmaz, A., Lindh, M., Nilsson, S., et al. (2020). Neurochemical evidence of astrocytic and neuronal injury commonly found in COVID-19. Neurology 95, e1754-e1759. doi: 10.1212/WNL.0000000000010111

Knuesel, I., Chicha, L., Britschgi, M., Schobel, S. A., Bodmer, M., Hellings, J. A., et al. (2014). Maternal immune activation and abnormal brain development across CNS disorders. Nat. Rev. Neurol. 10, 643-660. doi: 10.1038/nrneurol.2014.187

Krakowiak, P., Walker, C. K., Bremer, A. A., Baker, A. S., Ozonoff, S., Hansen, R. L., et al. (2012). Maternal metabolic conditions and risk for autism and other neurodevelopmental disorders. Pediatrics 129, e1121-1128. doi: 10.1542/peds.2011-2583

Lau, K. K., Yu, W. C., Chu, C. M., Lau, S. T., Sheng, B., and Yuen, K. Y. (2004). Possible central nervous system infection by SARS coronavirus. Emerg. Infect. Dis. 10, 342-344. doi: 10.3201/eid1002.030638

Lechien, J. R., Chiesa-Estomba, C. M., De Siati, D. R., Horoi, M., Le Bon, S. D., Rodriguez, A., et al. (2020). Olfactory and gustatory dysfunctions as a clinical presentation of mild-to-moderate forms of the coronavirus disease (COVID-19): a multicenter European study. Eur. Arch. Otorhinolaryngol. 277, 2251-2261. doi: 10.1007/s00405-020-05965-1

Lee, B. K., Magnusson, C., Gardner, R. M., Blomstrom, A., Newschaffer, C. J., Burstyn, I., et al. (2015). Maternal hospitalization with infection during pregnancy and risk of autism spectrum disorders. Brain Behav. Immun. 44, 100-105. doi: 10.1016/j.bbi.2014.09.001

Li, W., Henderson, L. J., Major, E. O., and Al-Harthi, L. (2011). IFN-gamma mediates enhancement of HIV replication in astrocytes by inducing an antagonist of the beta-catenin pathway (DKK1) in a STAT 3-dependent manner. J. Immunol. 186, 6771-6778. doi: 10.4049/jimmunol.1100099

Li, X., Chauhan, A., Sheikh, A. M., Patil, S., Chauhan, V., Li, X. M., et al. (2009). Elevated immune response in the brain of autistic patients. J. Neuroimmunol. 207, 111-116. doi: 10.1016/j.jneuroim.2008.12.002

Liao, X., Liu, Y., Fu, X., and Li, Y. (2020). Postmortem studies of neuroinflammation in autism spectrum disorder: a systematic review. Mol. Neurobiol. 57, 3424-3438. doi: 10.1007/s12035-020-01976-5

Lima, M. E. S., Barros, L. C. M., and Aragao, G. F. (2020). Could autism spectrum disorders be a risk factor for COVID-19? Med. Hypothes. 144, 109899. doi: 10.1016/j.mehy.2020.109899

Mazon-Cabrera, R., Vandormael, P., and Somers, V. (2019). Antigenic targets of patient and maternal autoantibodies in autism spectrum disorder. Front. Immunol. 10, 1474. doi: 10.3389/fimmu.2019.01474

Merad, M., and Martin, J. C. (2020). Pathological inflammation in patients with COVID-19: a key role for monocytes and macrophages. Nat. Rev. Immunol. 20, 355-362. doi: 10.1038/s41577-020-0331-4

Minakova, E., and Warner, B. B. (2018). Maternal immune activation, central nervous system development and behavioral phenotypes. Birth Defects Res. 110, 1539-1550. doi: 10.1002/bdr2.1416

Moore, J. B., and June, C. H. (2020). Cytokine release syndrome in severe COVID19. Science 368, 473-474. doi: 10.1126/science.abb8925
Mullins, E., Evans, D., Viner, R. M., O’Brien, P., and Morris, E. (2020). Coronavirus in pregnancy and delivery: rapid review. Ultrasound Obstet. Gynecol. 55, 586-592. doi: 10.1002/uog.22014

Nemoto, W., Yamagata, R., Nakagawasai, O., Nakagawa, K., Hung, W. Y., Fujita, M., et al. (2020). Effect of spinal angiotensin-converting enzyme 2 activation on the formalin-induced nociceptive response in mice. Eur. J. Pharmacol. 872, 172950. doi: 10.1016/j.ejphar.2020.172950

Ormstad, H., Bryn, V., Saugstad, O. D., Skjeldal, O., and Maes, M. (2018). Role of the immune system in autism spectrum disorders (ASD). CNS Neurol. Disord. Drug. Targets 17, 489-495. doi: 10.2174/1871527317666180706123229

Pardo, C. A., and Eberhart, C. G. (2007). The neurobiology of autism. Brain Pathol. 17, 434-447. doi: 10.1111/j.1750-3639.2007.00102.x

Patterson, P. H. (2009). Immune involvement in schizophrenia and autism: etiology, pathology and animal models. Behav. Brain Res. 204, 313-321. doi: 10.1016/j.bbr.2008.12.016

Petrelli, F., Pucci, L., and Bezzi, P. (2016). Astrocytes and microglia and their potential link with autism spectrum disorders. Front. Cell Neurosci. 10, 21. doi: $10.3389 /$ fncel.2016.00021

Polidoro, R. B., Hagan, R. S., de Santis Santiago, R., and Schmidt, N. W. (2020). Overview: systemic inflammatory response derived from lung injury Caused by SARS-CoV-2 infection explains severe outcomes in COVID-19. Front. Immunol. 11, 1626. doi: 10.3389/fimmu.2020.01626

Rasile, M., Lauranzano, E., Mirabella, F., and Matteoli, M. (2021). Neurological consequences of neurovascular unit and brain vasculature damages: potential risks for pregnancy infections and COVID-19-babies. FEBS J. doi: 10.1111/febs.16020. [Epub ahead of print].

Rasmussen, S. A., Smulian, J. C., Lednicky, J. A., Wen, T. S., and Jamieson, D. J. (2020). Coronavirus Disease 2019 (COVID-19) and pregnancy: what obstetricians need to know. Am. J. Obstet. Gynecol. 222, 415-426. doi: 10.1016/j.ajog.2020.02.017

Reichard, R. R., Kashani, K. B., Boire, N. A., Constantopoulos, E., Guo, Y., and Lucchinetti, C. F. (2020). Neuropathology of COVID-19: a spectrum of vascular and acute disseminated encephalomyelitis (ADEM)-like pathology. Acta Neuropathol. 140, 1-6. doi: 10.1007/s00401-020-02166-2

Riikonen, R., Makkonen, I., Vanhala, R., Turpeinen, U., Kuikka, J., and Kokki, H. (2006). Cerebrospinal fluid insulin-like growth factors IGF1 and IGF-2 in infantile autism. Dev. Med. Child Neurol. 48, 751-755. doi: $10.1017 /$ S0012162206001605

Riley, E. P., and McGee, C. L. (2005). Fetal alcohol spectrum disorders: an overview with emphasis on changes in brain and behavior. Exp. Biol. Med. 230, 357-365. doi: 10.1177/15353702-0323006-03

Sakers, K., and Eroglu, C. (2019). Control of neural development and function by glial neuroligins. Curr. Opin. Neurobiol. 57, 163-170. doi: 10.1016/j.conb.2019.03.007

Sasannejad, C., Ely, E. W., and Lahiri, S. (2019). Long-term cognitive impairment after acute respiratory distress syndrome: a review of clinical impact and pathophysiological mechanisms. Crit. Care 23, 352. doi: 10.1186/s13054-019-2626-z

Satarker, S., and Nampoothiri, M. (2020). Involvement of the nervous system in COVID-19: The bell should toll in the brain. Life Sci. 262, 118568. doi: 10.1016/j.lfs.2020.118568

Saxena, R., Babadi, M., Namvarhaghighi, H., and Roullet, F. I. (2020). Role of environmental factors and epigenetics in autism spectrum disorders. Prog. Mol. Biol. Transl. Sci. 173, 35-60. doi: 10.1016/bs.pmbts.2020.05.002

Scuderi, C., and Verkhratsky, A. (2020). The role of neuroglia in autism spectrum disorders. Prog. Mol. Biol. Transl. Sci. 173, 301-330. doi: 10.1016/bs.pmbts.2020.04.011

Shi, Y., Wang, Y., Shao, C., Huang, J., Gan, J., Huang, X., et al. (2020). COVID19 infection: the perspectives on immune responses. Cell. Death Differ. 27, 1451-1454. doi: 10.1038/s41418-020-0530-3

Smith, S. E., Li, J., Garbett, K., Mirnics, K., and Patterson, P. H. (2007). Maternal immune activation alters fetal brain development through interleukin-6. J. Neurosci. 27, 10695-10702. doi: 10.1523/JNEUROSCI.2178-07.2007

Soung, A., and Klein, R. S. (2018). Viral encephalitis and neurologic diseases: focus on astrocytes. Trends. Mol. Med. 24, 950-962. doi: 10.1016/j.molmed.2018.09.001

Spinato, G., Fabbris, C., Polesel, J., Cazzador, D., Borsetto, D., Hopkins, C., et al. (2020). Alterations in smell or taste in mildly symptomatic outpatients 
with SARS-CoV-2 infection. JAMA 323, 2089-2090. doi: 10.1001/jama.2020. 6771

Steardo, L., Steardo, L. Jr., Zorec, R., and Verkhratsky, A. (2020a). Neuroinfection may contribute to pathophysiology and clinical manifestations of COVID-19. Acta Physiol. 229, e13473. doi: 10.1111/apha.13473

Steardo, L. J., Steardo, L., and Verkhratsky, A. (2020b). Psychiatric face of COVID19. Transl. Psychiatry 10, 261. doi: 10.1038/s41398-020-00949-5

Steardo, L. Jr., Steardo, L., Verkhratsky, A., and Scuderi, C. (2021). Post-COVID19 neuropsychiatric syndrome: Is maladaptive glial recovery to blame? Acta Physiol. 22, e13717. doi: 10.1111/apha.13717

Steinman, G. (2020a). COVID-19 and autism. Med. Hypotheses 142, 109797. doi: 10.1016/j.mehy.2020.109797

Steinman, G. (2020b). The putative etiology and prevention of autism. Prog. Mol. Biol. Transl. Sci. 173, 1-34. doi: 10.1016/bs.pmbts.2020.04.013

Stogsdill, J. A., Ramirez, J., Liu, D., Kim, Y. H., Baldwin, K. T., Enustun, E., et al. (2017). Astrocytic neuroligins control astrocyte morphogenesis and synaptogenesis. Nature 551, 192-197. doi: 10.1038/nature24638

Supekar, K., Uddin, L. Q., Khouzam, A., Phillips, J., Gaillard, W. D., Kenworthy, L. E., et al. (2013). Brain hyperconnectivity in children with autism and its links to social deficits. Cell Rep 5, 738-747. doi: 10.1016/j.celrep.2013.10.001

Taquet, M., Geddes, J. R., Husain, M., Luciano, S., and Harrison, P. J. (2021). 6-month neurological and psychiatric outcomes in 236379 survivors of COVID-19: a retrospective cohort study using electronic health records. Lancet Psychiatry 8, 416-427. doi: 10.1016/S2215-0366(21)00084-5

Tavcar, P., Potokar, M., Kolenc, M., Korva, M., Avsic-Zupanc, T., Zorec, R., et al. (2021). Neurotropic Viruses, Astrocytes, and COVID-19. Front. Cell Neurosci. 15, 662578. doi: 10.3389/fncel.2021.662578

Tremblay, M. E., Madore, C., Bordeleau, M., Tian, L., and Verkhratsky, A. (2020). Neuropathobiology of COVID-19: the role for glia. Front Cell Neurosci 14, 592214. doi: 10.3389/fncel.2020.592214

Vaira, L. A., Salzano, G., Deiana, G., and De Riu, G. (2020). Anosmia and ageusia: common findings in COVID-19 patients. Laryngoscope 130, 1787. doi: 10.1002/lary.28692

Valenza, M., Facchinetti, R., Steardo, L., and Scuderi, C. (2020). Altered waste disposal system in aging and Alzheimer's disease: focus on astrocytic aquaporin-4. Front. Pharmacol. 10:1656. doi: 10.3389/fphar.2019.01656

Verkhratsky, A., Zorec, R., and Parpura, V. (2017). Stratification of astrocytes in healthy and diseased brain. Brain Pathol. 27, 629-644. doi: 10.1111/bpa.12537

Virhammar, J., Kumlien, E., Fallmar, D., Frithiof, R., Jackmann, S., Skold, M. K., et al. (2020). Acute necrotizing encephalopathy with SARSCoV-2 RNA confirmed in cerebrospinal fluid. Neurology 95, 445-449. doi: 10.1212/WNL.0000000000010250

Vivanti, A. J., Vauloup-Fellous, C., Prevot, S., Zupan, V., Suffee, C., Do Cao, J., et al. (2020). Transplacental transmission of SARS-CoV-2 infection. Nat. Commun. 11, 3572. doi: 10.1038/s41467-020-17436-6

Wolfel, R., Corman, V. M., Guggemos, W., Seilmaier, M., Zange, S., Muller, M. A., et al. (2020). Virological assessment of hospitalized patients with COVID-2019. Nature 581, 465-469. doi: 10.1038/s41586-0202196-x

Woodworth, K. R., Olsen, E. O., Neelam, V., Lewis, E. L., Galang, R. R., Oduyebo, T., et al. (2020). Birth and infant outcomes following laboratory-confirmed SARS-CoV-2 infection in pregnancy - SET-NET, 16 jurisdictions. MMWR Morb. Mortal. Wkly. Rep. 69, 1635-1640. doi: 10.15585/mmwr.mm6944e2
Xu, J., Zhong, S., Liu, J., Li, L., Li, Y., Wu, X., et al. (2005). Detection of severe acute respiratory syndrome coronavirus in the brain: potential role of the chemokine mig in pathogenesis. Clin. Infect. Dis. 41, 1089-1096. doi: 10.1086/444461

Yan, J., Guo, J., Fan, C., Juan, J., Yu, X., Li, J., et al. (2020). Coronavirus disease 2019 in pregnant women: a report based on 116 cases. Am. J. Obstet. Gynecol. 223, 111 e111-111 e114. doi: 10.1016/j.ajog.2020.04.014

Zaigham, M., and Andersson, O. (2020). Maternal and perinatal outcomes with COVID-19: a systematic review of 108 pregnancies. Acta Obstet. Gynecol. Scand. 99, 823-829. doi: 10.1111/aogs.13867

Zeidan-Chulia, F., Salmina, A. B., Malinovskaya, N. A., Noda, M., Verkhratsky, A., and Moreira, J. C. (2014). The glial perspective of autism spectrum disorders. Neurosci. Biobehav. Rev. 38, 160-172. doi: 10.1016/j.neubiorev.2013. 11.008

Zeisel, A., Munoz-Manchado, A. B., Codeluppi, S., Lonnerberg, P., La Manno, G., Jureus, A., et al. (2015). Brain structure. Cell types in the mouse cortex and hippocampus revealed by single-cell RNA-seq. Science 347, 1138-1142. doi: 10.1126/science.aaa1934

Zeng, H., Xu, C., Fan, J., Tang, Y., Deng, Q., Zhang, W., et al. (2020). Antibodies in infants born to mothers with COVID-19 pneumonia. JAMA 323, 1848-1849. doi: 10.1001/jama.2020.4861

Zhou, B. Y., Liu, Y., Kim, B., Xiao, Y., and He, J. J. (2004). Astrocyte activation and dysfunction and neuron death by HIV-1 Tat expression in astrocytes. Mol. Cell. Neurosci. 27, 296-305. doi: 10.1016/j.mcn.2004.07.003

Zhou, Z., Kang, H., Li, S., and Zhao, X. (2020). Understanding the neurotropic characteristics of SARS-CoV-2: from neurological manifestations of COVID19 to potential neurotropic mechanisms. J. Neurol. 267, 2179-2184. doi: 10.1007/s00415-020-09929-7

Zhu, Z., Cai, T., Fan, L., Lou, K., Hua, X., Huang, Z., et al. (2020). Clinical value of immune-inflammatory parameters to assess the severity of coronavirus disease 2019. Int. J. Infect. Dis. 95, 332-339. doi: 10.1016/j.ijid.2020 .04 .041

Zorec, R., Zupanc, T. A., and Verkhratsky, A. (2019). Astrogliopathology in the infectious insults of the brain. Neurosci. Lett. 689, 56-62. doi: 10.1016/j.neulet.2018.08.003

Conflict of Interest: The authors declare that the research was conducted in the absence of any commercial or financial relationships that could be construed as a potential conflict of interest.

Publisher's Note: All claims expressed in this article are solely those of the authors and do not necessarily represent those of their affiliated organizations, or those of the publisher, the editors and the reviewers. Any product that may be evaluated in this article, or claim that may be made by its manufacturer, is not guaranteed or endorsed by the publisher.

Copyright (c) 2021 Valenza, Steardo, Steardo, Verkhratsky and Scuderi. This is an open-access article distributed under the terms of the Creative Commons Attribution License (CC BY). The use, distribution or reproduction in other forums is permitted, provided the original author(s) and the copyright owner(s) are credited and that the original publication in this journal is cited, in accordance with accepted academic practice. No use, distribution or reproduction is permitted which does not comply with these terms. 